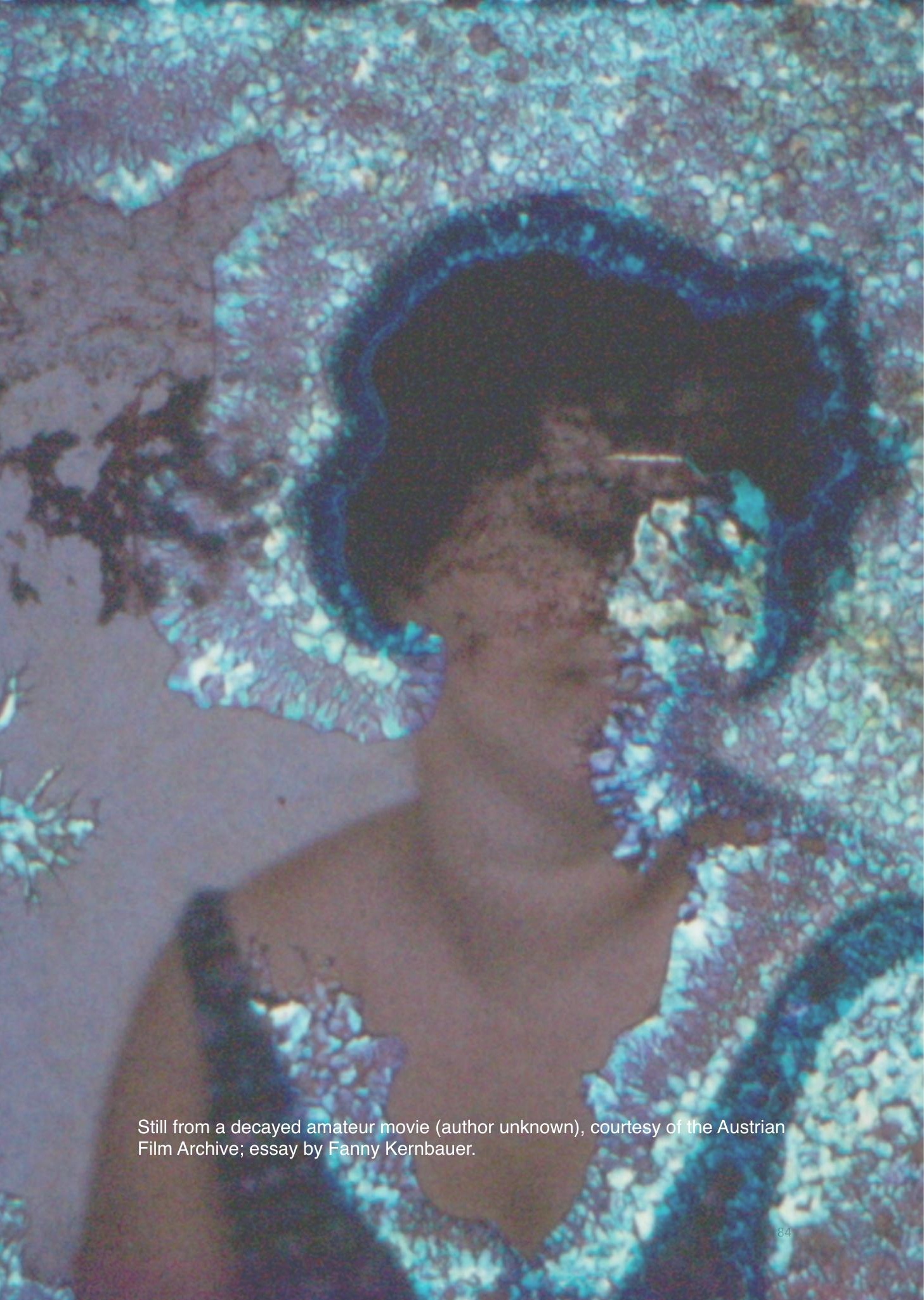




\section{The Aesthetics of Decay: An Homage to the Beauty of Transience}

\section{Fanny Kernbauer}

First and foremost, I want to introduce the film which inspired this essay. Not much is known about the footage. It is an amateur film without sound, shot in the second half of the 20th century, possibly in the 60s. Flowers, mountains, laughing children; what we see is what was meant to be seen and remembered: the good times (Gütermann 2015). But the film is dissolving and eroding, due to poor caretaking and the exposure to light and moisture. This very process of decay accounts for the strong visual experience we have when watching it now. The black and blue arms reach into the picture, almost as if to wipe out the memory of the people depicted. At some points, it is barely possible to make out what was being filmed. All you can see are the blossoms of slow death taking over the image, taking back what is theirs. It is a manifestation of the beauty and the pain of time. The irony here is that the very results of decay, which we bear witness to, qualify the film as art. The film has the power to draw the spectator into the moving pictures; the appearance and the retreating of the blue veil following the rhythm of the life they tried to encapsulate. A damaged amateur movie becomes an artwork, a homage to the passage of time. This opens up a number of questions. First of all, we are dealing with artwork which owes its mystery and fascination, not to the genius of an artist but the most natural process of decomposition. It is an artwork without an artist. The history of this artefact has itself shaped it into an artwork. This aspect is directly linked to the question of an aesthetics of decay: Why do signs of decay or, for that matter, even error, appeal to us aesthetically?

When writing about the experience of wonder, Greenblatt observes that 'the heart of the mystery lies with the uniqueness, authenticity, and visual power of the masterpiece, ideally displayed in such a way as to heighten its charisma, to compel and reward the intensity of the viewer's gaze, to manifest artistic genius' (Greenblatt 1991, 51). It is indeed legitimate to compare the experience we have when watching the film to the mode of wonder which Greenblatt goes on to describe as a state of enchanted looking 'when the act of attention draws a circle around itself from which everything but the object is excluded, when intensity of regard blocks out all circumambient images, stills all murmuring voices' (Greenblatt 1991, 49). However, Greenblatt's description is bound to the 'artistic genius', to the skilful composition of the masterpiece. This inevitably raises the question of what it is that evokes the experience of wonder in the spectator when it is clearly not the skill or genius of the artist.

I argue that it is precisely the fact that there is no artist, that there is no artistic mind behind it, but only the all-consuming power of time and its material manifestation on the film itself which makes the experience so compelling and that this longing for naturalness not only in art but in general is very particular to the time we live in today. I am going to illustrate this argument by means of two aspects. The first concerns the essence and the characteristics of the society and its normative systems within which we move and live. The social order surrounding us is strongly marked by regulatory systems and strategies which are, as Edensor writes, continuously followed to ensure the stability of meaning and purpose (Edensor 2005, 313). Personal and social identity, more often 
than not, depend on the stability and fixity of this order which is maintained through constructing networks which variously comprise objects, humans, spaces, technologies and forms of knowledge (Law 1993). Hence, there is very little room for disorder and error, given that space is meticulously divided into discrete, functional, single-purpose realms (Sibley 1988). These ordering and regulating mechanisms which are built on the principle of control and the illusion of permanence, I argue, go hand in hand with an expulsion of disorder, decay, error, weakness and death, which, needless to say, is rather unnatural. Considering the sensory impact of ruins on the spectator and the contrast in which they stand to our urban surroundings, Edensor writes: 'In desensualized urban and domestic realms, the sheer smoothness of space, the constant maintenance of space and objects through cleaning, polishing and disposal effectively restricts and regulates sensory experience (...) The reproduction of smoothed over space not only involves a control of matter but also conforms to ideas about how the 'modern' body should comport itself in the city, how it should apprehend and sense the city in accordance with 'efficient' and 'healthy' norms which banish material and sensual clutter, creating seamless walkways, clear and linear sight-lines, deodorized environments, highly regulated soundscapes and smooth tactilities within which bodies are enabled and coerced to perform in appropriate, "rational" ways' (Edensor, 2005: 324).

This illustrates how the above-mentioned regulating mechanisms help to uphold a façade of seamless order. Referring to the film, the manifestation of decay breaks through this façade and contributes to the visual experience of the spectator who gets a glimpse of a state recalling the film's own construction (Edensor 2005, 318) and revealing the boundaries of its function to immortalize what cannot be immortal. The illusion of permanence and control lifts its veil and reveals the artifice through which order had been maintained and structured to withstand ambiguity (Edensor 2005, 320). This, in my opinion, accounts for the attraction we feel towards things and forces which underlie a power transcending the possibility of human control; things, which are fluid as well as opaque and resistant to fixity (Neville and Villeneuve, 2002: 5). It is this resistance to regulation, rationalization and categorization where the fascination for something beyond control originates. The film, therefore, tells a tale about life and death and the inseparableness of the two. It appeals to people's hidden knowledge of the transience of all things.

The second aspect concerns the art world in particular. I argue that there is an increasing intellectualization of the arts, which hinders people from experiencing the very mode of wonder described above. This is particularly the case for political and conceptual art, which are very dependent on language and intellect. The most prominent feature of conceptual art or conceptualism is its proclamation to be an art of the mind rather than of the senses. Art, so to say, is in this sense more about intellectual inquiry and reflection rather than beauty and aesthetic pleasure ('Conceptual Art', Stanford Encyclopedia of Philosophy). Concepts and ideas are thus more important than the artwork itself. The visualization of the intellectual process of the artist is, therefore, the very purpose and centre of attention. As Henry Flynt wrote in his famous essay Concept Art: "Concept art" is first of all an art of which the material is "concepts", as the material for ex. music is sound' (Flynt 1963). He goes on to state that "since "concepts" are closely bound up with language, concept art is a kind of art of which the material is language' (Flynt 1963). This illustrates very clearly that the access 
to this kind of art and its works is closely bound to one's intellect, which inevitably adds to an elitist touch and increases the distance between the artwork and the beholder. The same goes for political art, since it is very rarely possible to understand and appreciate an artwork without knowing the artist's body of thought and the context of the work's origination. In a time when it is almost mandatory for an artist as well as his audience to take a political stand, it becomes increasingly challenging to create art which speaks to a higher truth than the social and political ideology.

I argue, however, that the aesthetics of decay and error offer access to the meaning of objects without having to climb the structure of thoughts built by the mind of the artist. Instead, the aesthetics of decay appeals to people's senses and thereby to a deeper understanding of life and the purpose of art, which lies not in the intellectual contest but rather in the possibility of an opening to a dimension which leads to a higher level of non-intellectual knowledge. This is not to say that this is the only means by which art can offer this experience to the spectator, but it might contribute to an understanding of why people are drawn to it the way they are. The film, for example, is neither in need of concepts nor language or even sound to leave a meaningful impression on the spectator. The effect it has is independent of the spectator's education, age or background because it speaks to a truth which lies above all social, cultural and intellectual orders and identities. It enables the viewer to get a glimpse of a meta-understanding of the essence of life, the power of time to which everything succumbs that cannot be expressed in words or intellectual concepts. And is this not precisely what art is about?

Edensor, Tim. 2005. 'Waste Matter - The Debris of Industrial Ruins and the Disordering of the Material World' Journal of Material Culture 10(3): 311-332.

Greenblatt, Stephen. 1991. 'Resonance and Wonder', In: Karp, I \& Lavington, F (eds) Exhibiting Cultures: The Politics and Poetics of Museum Display, Washington DC: Smithsonian Institution Press.

Gütermann, Nicolai S. 'Blüten des Bösen: Eine Schmalfilmrolle im Stadium des Zerfalls,' Der Standard, October 27, 2015.

Law, John. 1993. Organising Modernity: Social Order and Social Theory. Oxford: Blackwell.

Neville, Brian and Villeneuve, Johanne. 2002. 'Introduction: in Lieu of Waste', in Brian Neville and Johanne Villeneuve (eds) Waste-Site Stories: The Recycling of Memory, pp. 1-25. Albany: State University of New York Press.

Sibley, David .1988. 'Purification of Space', Environment and Planning D: Society and Space 6: 409-21.

Flynt, Henry. 1963. "Concept Art," accessed July 23, 2017, http:// www.henryflynt.org/aesthetics/conart.html

'Conceptual Art,' Stanford Encyclopedia of Philosophy, accessed July 23, 2017, https://plato.stanford.edu/entries/conceptual-art/. 